\author{
An Empirical Test of Value-Based Planning Models and Implications \\ Author(s): Carolyn Y. Woo \\ Source: Management Science, Vol. 30, No. 9 (Sep., 1984), pp. 1031-1050 \\ Published by: INFORMS \\ Stable URL: http://www.jstor.org/stable/2631722 \\ Accessed: 14/08/2009 00:04
}

Your use of the JSTOR archive indicates your acceptance of JSTOR's Terms and Conditions of Use, available at http://www.jstor.org/page/info/about/policies/terms.jsp. JSTOR's Terms and Conditions of Use provides, in part, that unless you have obtained prior permission, you may not download an entire issue of a journal or multiple copies of articles, and you may use content in the JSTOR archive only for your personal, non-commercial use.

Please contact the publisher regarding any further use of this work. Publisher contact information may be obtained at http://www.jstor.org/action/showPublisher?publisherCode=informs.

Each copy of any part of a JSTOR transmission must contain the same copyright notice that appears on the screen or printed page of such transmission.

JSTOR is a not-for-profit organization founded in 1995 to build trusted digital archives for scholarship. We work with the scholarly community to preserve their work and the materials they rely upon, and to build a common research platform that promotes the discovery and use of these resources. For more information about JSTOR, please contact support@jstor.org. 


\title{
AN EMPIRICAL TEST OF VALUE-BASED PLANNING MODELS AND IMPLICATIONS*
}

\author{
CAROLYN Y. WOO \\ Krannert Graduate School, Purdue University, West Lafayette, Indiana 47907
}

\begin{abstract}
The value of the firm is clearly the central purpose of most entrepreneurial activities. Considering the scope, nature and impact of Strategic Management decisions, one would expect firm value to be an integral concern of this area. Yet seldom do we observe value being explicitly managed or systematically linked to the strategies and direction of the firm.

Recent economic pressures are escalating the need to achieve a more complete and concrete portrayal of this relationship. In this search, a small number of frameworks have sprung up from traditional finance models to describe the value creation/destruction process from the strategic management perspective.

Though these models have generated strong interest and have provided useful insights, they have not been subjected to large-scale empirical evaluation. This research examined two frameworks and assessed the degree of empirical support for their implications.

Based on 4000 observations in 40 industries over a ten-year period, the current effort provided only partial support for the models and their implications. This paper supported the qualitative contributions of these models to better decision-making processes. Their statistical explanatory power, however, was not demonstrated.

(PLANNING)
\end{abstract}

\section{Introduction}

Through the process of planning and resource allocation, Strategic Management seeks to achieve the optimal match between the firm's internal resources and external environment. The success of the firm in this endeavor is commonly gauged by levels of profitability, growth and relative competitive position. Increasingly, serious attention is drawn to an additional performance criterion in the form of value generated for shareholders. This growing emphasis places pressure upon the firm to assess the productivity of all its decisions in light of economic benefits to its owners relative to their opportunity cost of capital. This issue of shareholder wealth maximization is fundamental to students and practitioners of Financial Management, yet with all candor, this criterion is not yet integrated into the Strategic Management process of goal formulation and strategy evaluation.

Growing attention, however, has spawned the development of a family of models, loosely known as value-based planning techniques. These models attempt to define and quantify the linkage between corporate-level variables and firm value in contexts which are relevant to the new audience, strategic managers. These frameworks are derived from the rather familiar discounted cash flow model (DCF), now shifted from its primary use in project analysis to the evaluation of corporate-level goals, strategies and performance.

In the first context as related to capital budgeting, the DCF model has proven to be an indismissible decision heuristic and its application problems are generally well understood. In the strategic planning context however, such confidence has not yet been earned. A key obstacle rests on the absence of published empirical evaluation and limited reports of user experience. On the one hand, these techniques have served to provide solutions and focus interest on the overdue issue of shareholder value in

*Accepted by Ambar G. Rao; received May 11, 1983. 
Strategic Management. Yet the extent to which these models do indeed provide an accurate representation of the linkage between shareholder value and firm action is not at all clear.

In light of the absence of empirical investigation, the objective of this paper is (1) to undertake a large-scale validation of the relationships reflected in two value-based models - the constant growth model and the two-stage model; and (2) to evaluate the predictive power of the constant growth model in over 400 companies across 40 industries. Empirical investigation of these models is seen as critical as continual pressures to effectively manage shareholder value accelerate the adoption of these value-based planning techniques.

\section{Shareholder Value}

Value, as a term, has many definitions. ${ }^{1}$ In the context of the firm, value commonly refers to its on-going cash generation potential. More specifically, value is a rationally determined or economic estimate based on the expected cash stream of a firm discounted by a factor which incorporates inflation and the nondiversifiable risk of the firm. As such, this estimate reflects the expected worth or intrinsic value of the firm.

The value of the firm, by which shareholder wealth is augmented, constitutes the central concern to investors. A firm generates, preserves or reduces shareholder wealth through all decisions it undertakes but particularly through those with significant impact. Strategic decisions are generally characterized by large resource commitments, broad impact throughout the organization, lasting effects and payoffs of significant magnitudes. As demonstrated in the following examples, these decisions have tremendous leverage over the value of the firm.

Victoria Station restaurant eroded value when it failed to diversify from its dependence on beef and on a middle class customer segment. Caught in the seventies against soaring beef prices, change in consumer preferences away from beef and declining real disposable income, the restaurant chain became highly unprofitable and its value fell sharply. ${ }^{2}$

In a highly cyclical and turbulent industry, Deere and Company created value through a strategy of focus and aggressive market share building. In the last decade, Deere had the most efficient operations, lowest cost, best products and the strongest dealer network. On the average, Deere's equity was valued at 50 percent higher than the industry and 100 percent over a leading competitor, International Harvester. ${ }^{3}$

A well-designed diversification program enabled Beatrice Foods to greatly reduce its

\footnotetext{
${ }^{1}$ Value as a term has been used to indicate actual, appraised assessed, book, breakup, carrying, real, reproductive, depreciated, face, fair, fair-market, going concern, insurable, intangible, intrinsic, liquidating market, residual, sound and true Value. (See McCarthy and Healey 1971, p. 3.)

${ }^{2}$ The average fiscal year-end market to book ratio of Victoria Station's shares fell from 2.34 in 1973-1976 to 0.96 in $1977-1980$.

For Victoria Station Restaurants references, see:

(a) "Victoria Station Eyes End to Financial Woes," Nation's Restaurant News, (23 November 1981), 54.

(b) "Victoria Station Incorporated," Moody's OTC Industrial Manual, (1981), 700-701.

(c) "Victoria Station Uncorks New Wine Program," Restaurant Business, (1 December 1981), 80, 82-3.

(d) Value Line, (8 January 1982), 333.

${ }^{3}$ The average fiscal year-end market to book ratio of Deere and International Harvester were 1.03 and 0.50 respectively between the time period 1975-1979.
}

For Deere and Company references, see:

(a) "Deere: A Counter Cyclical Expansion to Grab Market Share," Business Week, (November 19, 1979), 79-80.

(b) "Deere \& Company Farm Machinery Leadership Helps Firm Weather the Industry's Slump," The Wall Street Journal, (20 February 1981).

(c) Moody's Industrial Manual, (1981).

(d) Standard \& Poor's NYSE Stock Reports, (1978, 1981). 
exposure to the profit squeeze caused by uncertain supply and demand conditions surrounding agricultural commodities. In the seventies, Beatrice enjoyed a rate of return higher than the industry while its earnings variability was substantially lower. Through risk reduction and profitability gains, Beatrice was successful in creating value for the firm. ${ }^{4}$

In the above cases, value creation or erosion by the firms is clearly attributable to their product-market choices and strategic decisions to focus, diversify or build market share aggressively.

The value of the firm also impacts its ability to raise new equity capital. The attendant cost, capacity and degree of dilution are dependent on investors' appraisal of the firm's value. Considering the high cost of capital, the host of other financial instruments seeking investors' support and the lower multiples at which companies have been trading, ${ }^{5}$ few can dismiss the competitive advantage accorded by strong equity values.

\section{Value-Based Planning Models}

Increasing recognition of the leverage of strategic managers to create value has spurred the development of decision heuristics to address this issue. The efforts of primarily a handful of consulting firms (Marakon Associates 1980; Strategic Planning Associates 1981) and academic scholars (Fruhan 1979; Rappaport 1981) have culminated in a family of frameworks, popularly referred to as value-based planning frameworks. These are so termed because they all relate the impact of various firm characteristics to some measure of shareholder value. In the ensuing discussion, this paper will focus on two such models.

\section{Constant Growth Model}

The basis of this model is the Gordon growth model ${ }^{6}$ which assumes an infinite dividend stream growing at a constant rate and a discount factor which does not change over this period. This is a simple version of the Discounted Cash Flow model though its attendant assumptions of constant growth and risk level are highly restrictive.

In the model, value is represented as:

$$
V=D_{1 /\left(K_{E}-g\right) \quad \text { where }}
$$

$V=$ Intrinsic Value of the equity of the firm,

$D_{1}=$ Dividend payment in the next period,

$g=$ Constant dividend growth rate,

$K_{E}=$ Cost of Equity.

Because firms differ significantly in their sales and equity volume, we of ten choose

${ }^{4}$ Between 1970-1978, the year-end average for Return on Equity to Cost of Equity ratio was 0.813 for the processed foods industry versus 1.108 for Beatrice Foods. The standard deviations for these two series were 0.1416 and 0.0374 respectively.

For Beatrice Foods references, see:

(a) "Beatrice Foods: Adding Tropicana for Broader Nationwide Network," Business Week, (May 15, 1978), 114-116.

(b) "Beatrice Foods Savors a Zestier Cupboard," Business Week, (December 1, 1973), 89-90.

(c) "Beatrice the Acquisitive," Fortune, (June 15, 1975), 252.

(d) Value Line, (March 3, 1982), 893.

${ }^{5}$ The market to book ratios of the S\&P 400 had declined from 1.92 in 1970 to 1.43 in 1980 . The average market to book ratio from 1970 to 1975 was 2.08 and the comparable average from 1976 to 1980 was 1.34 . (Source: Statistical Service, Standard and Poor's, 1970-1981.)

${ }^{6}\left(G>K_{E}\right)$ is a necessary condition of the Gordon Growth Model. Further details are discussed in Copeland and Weston (1979, pp. 334-336). 
to look at earnings not on an absolute level, but as a ratio to sales (ROS), assets (ROA) or capital (ROI, ROE). Along the same line, it provides a more meaningful scale to compare the intrinsic value of the firm's equity to its corresponding book capital. The relative intrinsic value of the firm's equity to its book value $(V / B)$ can be represented by:

$$
\begin{aligned}
& \frac{V}{B}=\frac{D_{1} / B}{K_{E}-g} \quad \text { or ultimately, } \\
& \frac{V}{B}=\frac{R O E-g}{K_{E}-g}, \quad \text { where }
\end{aligned}
$$

$V / B=$ Ratio of intrinsic value to Book value of a firm's equity.

Application of this model is evident in the consulting frameworks adopted by the Strategic Planning Associates (1981), and Marakon Associates (Marakon 1981; Fortune 1981). The model has also been used in two Business Policy theses (Cobb 1981; Burgman 1982). The Cobb thesis utilized the model to estimate the individual intrinsic value of Martin Marietta's businesses. In the Burgman study, the model was used to measure the attractiveness of acquisition candidates. Both theses encountered modelling problems and demonstrated the sensitivity of the model to the long-term growth and ROE parameters supplied as data inputs. Cobb (1981) had greater success in resolving the estimation difficulties after first-hand knowledge of the sample company provided for extensive adjustments of these long-term parameters.

\section{Two-Stage Model (Fruhan)}

This model proposed by Fruhan (1979) depicts a firm with two stages of development. The first stage is characterized by a rate of return on equity either greater than or less than the cost of equity. Neither condition can be sustained indefinitely. In the first instance, the implicit economic rent will be eroded through competitive entry, government regulation, technological changes or shifts in consumer preferences; in the second, the firm will continue to erode the value of its equity until liquidation or loss of control become inevitable. The second stage which follows represents an equilibrium period when the firm's return on equity maintains parity with its cost of equity. In this stage, there is neither positive nor negative rent, and, hence, no value is created or destroyed.

In this model, intrinsic value $(V)$ and the valuation ratio $(V / B)$ are respectively:

$$
\begin{gathered}
V=\left[\sum_{i=1}^{n} \frac{E q_{0}(1+\operatorname{ROE}(r))^{i-1} \operatorname{ROE}(1-r)}{\left(1+K_{E}\right)^{i}}\right]+\frac{E q_{0}(1+\operatorname{ROE}(r))^{n}}{\left(1+K_{E}\right)^{n}}, \\
V / B=\left(\frac{1+\operatorname{ROE}(r)}{1+K_{E}}\right)^{n}+\frac{\operatorname{ROE}(1-r)}{K-\operatorname{ROE}(r)}\left[1-\left(\frac{\operatorname{ROE}(r)+1}{1+K_{E}}\right)^{n}\right], \quad \text { where }
\end{gathered}
$$

$V=$ Intrinsic value of the equity of the firm,

$E q_{0}=$ the current book equity of the firm,

$\mathrm{ROE}=$ Return on Equity in stage one,

$n=$ duration of stage one,

$r=$ retention in stage one,

$K_{E}=$ cost of equity,

$V / B=$ Intrinsic value to book value of equity.

Using this model (equation (5)), Fruhan (1979) estimated the valuation ratios of over 70 companies. In addition, Fruhan also conducted in-depth value analyses of seven case studies involving divestiture, internal growth, a creative financing arrangement 
and a destructive competitive posture. The author showed in the grocery retail and computer leasing industries that value creation or destruction takes place not only at the firm but also at the industry level. Fruhan had successfully broadened the use of valuation frameworks beyond the functional project context.

Without question, the model is still an oversimplification of the firm's reality. The two stages of growth and profitability would not capture the dynamic changes experienced by the firm. Yet, it represents an improvement over the constant growth model to the extent it accommodates a less rigid set of assumptions (two stages of firm development instead of one constant stage). Moreover, Fruhan's effort also illustrates how other multi-stage models can be similarly constructed.

\section{Model Implications for Value Creation}

In both models, parallel implications emerge to describe the conditions for value creation. Value is only created when the rate of return (ROE) exceeds the corresponding cost of the investment $\left(K_{E}\right)$. Positive accounting rates of return per se are not sufficient. These rates must more than recover the opportunity cost of the capital employed. Value is maintained when the rate of return equals investment costs. Similarly, value destruction occurs when the above conditions fail to take place.

$A$ rate of return which exceeds the cost of capital is a necessary and sufficient condition for value creation. This is true regardless of the rate of growth. When this condition fails to hold, higher growth rates will merely erode the value of the firm. Yet, when returns exceed the underlying cost, higher rates of growth will accelerate the value creation process. Growth can be compared to a catalyst which increases the rate of value erosion or creation depending on the firm's ability to meet the profitability constraint.

Formulated from well-accepted financial theories, these conditions are not meant to be surprising. What is more difficult to understand though is the lack of more explicit attention to the value consequence of strategies in the study and practice of Strategic Management. Seldom do these conditions enter into the definition of goals and objectives in both the normative and descriptive literature. Analytical frameworks for strategy formulation and evaluation frequently portray the impact of strategies on profitability, growth, competitive position but seldom on value. Organization theories also indicate the compromise of these conditions as managers seek to maximize growth while maintaining only a satisfying posture with respect to profitability (Baumol 1967).

Statistical data from a study on U.S. corporations also point to rather dismal value creation performance. In a sample of 400 firms across over 40 industries in two five-year periods (1970-74, 1975-79), Woo (1983) identified firms which recovered their cost of equity in at least four out of five years as value creators and others which managed to do so in no more than one out of five years as value destroyers. In this study, value destroyers outnumbered value creators by two and a half times to one. In light of the large proportion of firms which failed to earn their cost of capital, it appears that the value creation principles, while intuitive, have not yet played a recognizable role in either the practice or theory development of Strategic Management.

If not for new theoretical insight, why then the growing interest in value-based planning techniques? The answer is that these models provide a practical tool to quantitatively and explictly relate corporate decisions of growth, profitability and risk to shareholder welfare. While Strategic Management students and practitioners have always accepted the value preservation principle, now the mathematical models provide a much-needed sense of operational clarity, sharpening the variables and subsequent decisions which must be successfully managed to make value creation a reality, not merely a philosophy. All in all, these techniques are opening the gateways 
for strategic managers to venture into the arena of value management, a responsibility which so far does not appear to have been successfully met.

While the advent of value-based planning models will no doubt fill an important vacuum, attendant questions on model testing and validation must also be raised. To date, applications of these models have been documented in only a small number of cases and their reliability has not been demonstrated in any large sample context. Recall that the only large-scale application by Burgman (1982) was unsuccessful and yielded problematic estimates. The lack of systematic and large-scale testing must be redressed before widespread adoption should be strongly urged. Acknowledgement of the need for responsible advocation as well as the potential contribution of sound and proven heuristics for value management has prompted the current empirical investigation.

In the following sections, the explanatory power of Return on Equity, Cost of Equity and various growth series as determinants of firm value will first be assessed. The statistical fit of the Constant Growth Model will also be evaluated. A similar test will not be conducted on Fruhan's two-stage model in this current study since absence of first-hand knowledge precluded the estimation of the parameter $(n)$-i.e., the duration of the first stage or nonequilibrium period for each company.

\section{Research Framework}

\section{(1) Statement of Hypotheses}

In equations (3) and (5), the intrinsic value to book ratio is postulated as a function of three key corporate variables: profitability, nondiversifiable risk and growth. While the Fruhan two-stage model (equation (5)) did not directly incorporate any growth variable, the product of $(r)$ times (ROE) can be shown to be equivalent to the growth rate in shareholder equity or dividend. ${ }^{7}$ Four relationships emerge from the two value-based models and these constitute the focus of the following empirical analysis. They are:

Number
I $\quad \begin{aligned} & \text { Hypothesis } \\ & \text { valding all other variables constant, the intrinsic } \\ & \text { Equity, i.e., } V / B=F_{+}[\mathrm{ROE}]\end{aligned}$
II $\quad \begin{aligned} & \text { Holding all other variables constant, the intrinsic } \\ & \text { valuation ratio is a negative function of the Cost } \\ & \text { of Equity, i.e., } V / B=F_{-}\left[K_{E}\right]\end{aligned}$

${ }^{7}$ Growth in equity can be expressed as:

$$
\begin{aligned}
G \text { equity } & =\frac{E q_{1}-E q_{0}}{E q_{0}}=\frac{\text { Profits }_{1}-\text { Dividends }_{1}}{\text { Equity }_{0}}=\frac{\text { Profits }\left(\text { Profits }_{1}(1-\text { Retention })\right)}{\text { Equity }_{0}} \\
& =\frac{\text { Profits }_{1}}{\text { Equity }_{0}}-\frac{\text { Profits }_{1}}{\text { Equity }_{0}}+\frac{\text { Profits }_{1}}{\text { Equity }_{0}} \text { (Retention) } \\
& =\text { ROE }- \text { ROE }+ \text { ROE (Retention })=\text { ROE (Retention). }
\end{aligned}
$$

When the retention rate is constant. $G$ equity $=G$ dividend:

$$
\begin{aligned}
G \operatorname{div} . & =\frac{(1-\text { Retention })(\mathrm{ROE})\left(E q_{1}\right)-(1-\text { Retention })(\mathrm{ROE})\left(E q_{0}\right)}{(1-\text { Retention })(\mathrm{ROE})\left(E q_{0}\right)} \\
& =\left(E q_{1}-E q_{0}\right) / E q_{0}=G \text { equity. }
\end{aligned}
$$

Hence $G$ div. $=$ ROE (Retention). 


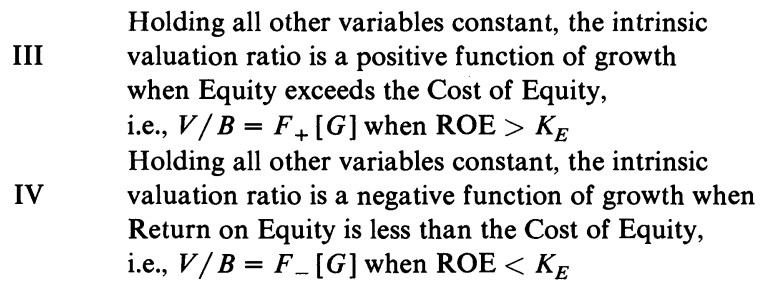

In addition, the statistical fit of the Constant Growth Model as stated in equation (3) and again in Hypothesis $\mathrm{V}$ will also be evaluated.

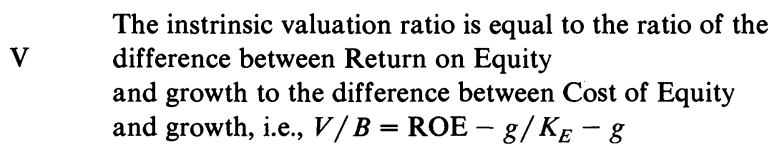

\section{(2) Model Specification}

The hypotheses were evaluated within the Multiple Regression framework. When appropriate, the models also included a Market index corresponding to the market to book ratio of the S\&P 400 for the corresponding year. This index incorporated the impact of market-wide effects. Through adjustments of the intercepts, it would also "segregate" the sample into more homogeneous time segments while providing the gains in degrees of freedom from cross-sectional, time series pooling. In the standardized form, the five hypotheses were tested through four different model specifications:

$$
\begin{aligned}
& \frac{V}{B}=A_{1} \mathrm{ROE}+A_{2} K_{E}+\sum_{i=1}^{5} A_{3_{i}} G_{i}+A_{4} M+u_{a}, \\
& \frac{V}{B}=B_{1} \mathrm{ROE}+B_{2} 1 / K_{E}+\sum_{i=1}^{5} B_{3_{i}} G_{i}+b_{4} M+u_{b}, \\
& \frac{V}{B}=C_{1} \mathrm{ROE} / K_{E}+\sum_{i=1}^{5} C_{2_{i}} G_{i}+C_{3} M+u_{c}, \\
& \frac{V}{B}=d_{1} \frac{\mathrm{ROE}-g}{K_{E}-g}+u_{d} .
\end{aligned}
$$

In light of the stated hypotheses, expectations of the coefficients can be summarized as in Table 1.

\section{(3) Variable Definitions}

To accommodate model sensitivity to the parameters supplied as inputs, this study provided alternative measures for the independent variables. A list of all measures

TABLE 1

Hypothesized Directions for Regression Coefficients

\begin{tabular}{lcccccc}
\hline & $\mathrm{ROE}$ & $K_{E}$ & $1 / K_{E}$ & $\mathrm{ROE} / K_{E}$ & $G i$ & $M$ \\
\hline total sample & + & - & + & + & uns & uns \\
$\mathrm{ROE}<K_{E}$ & + & - & + & + & - & uns \\
$\mathrm{ROE}>K_{E}$ & + & - & + & + & + & uns \\
\hline
\end{tabular}

$*$ uns $=$ unspecified 
Exhibit 1

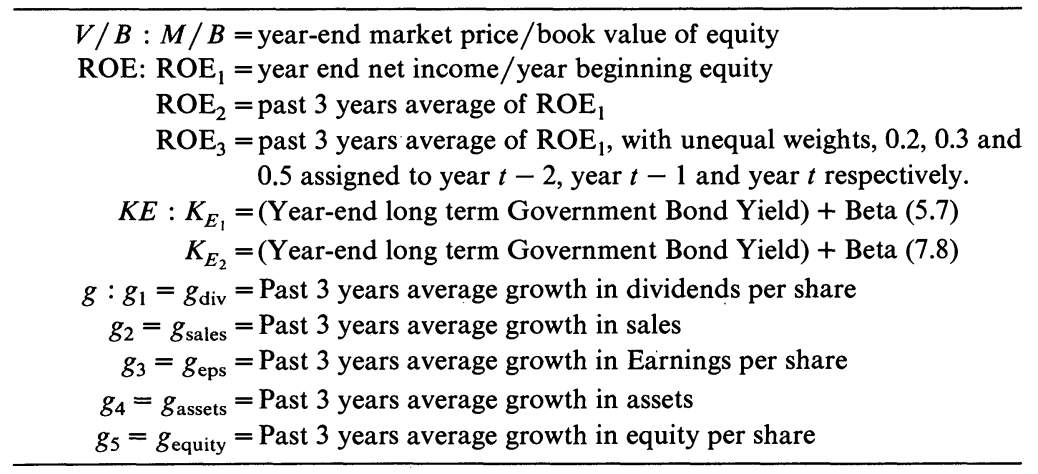

$M:$ Market index $=S+P 400$ year end Market to Book index

employed is defined in Exhibit 1. As a result of alternative variable measurements, the four models stated earlier were tested through 17 separate equations.

(a) Intrinsic Valuation Ratio $(V / B)$. Intrinsic value unfortunately cannot be observed, only inferred. The quality of this inference is directly dependent on investors' knowledge of the firm, its strengths, problems, opportunities and likely performance. What is readily observable and more operational in research is the market value of the firm, or the price attached to its traded shares. As argued by Archer and D'Ambrosio (1972), market value provides an unbiased measure of intrinsic value:

\begin{abstract}
"Although subject to some variation in meaning, to be more specific, the word value usually refers to the long-run capitalized value of an asset as it is appraised by a larger number of market participants. They take into account expected returns from alternative investment opportunities in assets that have risks comparable to the asset being evaluated. Since there is presumed to be some long run value toward which market prices will tend to conform, this idea is often referred to as intrinsic value or control value. It is the value of an asset that will prevail when all knowledgeable participants act rationally in evaluating the asset. In the long run, the market price of the asset will tend to conform to this intrinsic value" (p. 65).
\end{abstract}

The above sentiments are similary echoed by Salter and Weinhold (1979):

“... The notion of market value is the most appropriate point for thinking about the creation of real economic value because it is the least subjective estimate of what an asset or its income stream is worth" (p. 117).

Market value, subjected to the problems of improper signalling, speculation, sensitivity to short-term extraordinary events, is not a pure measure of the intrinsic worth of the firm. Yet in an efficient market, ${ }^{8}$ we can reasonably expect stock value to move towards levels consistent with the firm's true value creation potential. In this empirical effort, market value will serve as a proxy for firm value. The intrinsic valution ratio $(V / B)$ will likewise be represented by the Market price to book ratio $(M / B)$.

(b) Return on Equity. Return on Equity is represented by the ratio of year-end net income (after interest, after taxes) to year-beginning equity. Three measures of ROE reflecting different time horizons (one year and three years), and utilizing different weights (equal weights versus heavier weighted current years) were included in this study. See Exhibit 1 for exact definitions.

(c) Growth. Growth in five measures, dividends per share, sales, earnings per share, assets and equity per share, are included in this study. That the models only explicitly incorporate the dividend growth rate should not exclude the relevance of

${ }^{8}$ Market efficiency is supported in the empirical studies reported by Cootner (1964); Fama (1965); Sharpe (1970) and Francis and Archer (1971). 
these other growth series. Under conditions of stability (as those subsumed in both frameworks), equivalence of all five growth rates can be shown. ${ }^{9}$ Hence, this empirical effort adopted the more conservative choice of examining all five growth measures. Each measure reflected the average annual growth rates over the past three years. (See Exhibit 1.)

(d) Cost of Equity. Greater controversy surrounds the estimation of the cost of equity. Heavy debates challenge ${ }^{10}$ but fail to discourage the use of the Capital Asset Pricing Model (CAPM), the framework which provides for the quantification of this discount factor. Application problems also emerge with vastly different choices of CAPM parameter values. ${ }^{11}$ As specified by CAPM, the discount factor can be determined by:

$$
\text { Cost of Equity }=\text { Risk-free Rate }+ \text { Systematic risk (equity risk premium). }
$$

This study employed the year-end long-term Government Bond yield as a measure of the risk-free rate and the Value Line $B^{2}{ }^{12}$ as a measure of systematic risk. Included were two alternate measures of the equity risk premium corresponding to Ibbotson and Sinquefield's (1979) arithmetic (7.8\%) and geometric means (5.7\%) from their 1926-1978 series of investments return data. These choices were based on the author's preference for objective rather than subjective assignments of risk and followed precedence of earlier applications (Fruhan 1979; Slater and Weinhold 1979; Strategic Planning Associates 1981; Burgman 1982).

Overall, attention is drawn to the substitution of long-term equilibrium rates with historical measures for the independent variables ROE, $K_{E}$ and $g$. This choice resulted from the absence of reliable forecasts of these future equilibrium conditions. Despite necessity, this constraint parallels the predicament which not only researchers but industry users would also have to contend with. The fit of the models based on these historical estimates would give some indication of their reliance on yet unobservable future data and the subsequent burden which will be placed upon forecasting.

\section{(4) Data Base and Sample Design}

All accounting data on Return On Equity and the five growth series were obtained through the COMPUSTAT data tape. Year-end market price data were made available through the CRSP annual tapes. Value Line provided Betas which were handcollected for the estimation of the Cost of Equity.

The sample was selected from the COMPUSTAT Primary Industrial and Supplementary files consisting of 1,800 publicly traded U.S. corporations. The time period of analysis covered the decade from 1970 to 1979. Twelve hundred and twenty four companies satisfied the initial requirement of nonmissing data for the last five consecutive years of this time period. To maintain the hand collection of Beta values at a manageable scale, the sample was further reduced. The selection was designed to

\footnotetext{
${ }^{9}$ Under stable conditions when profit margin, asset turnover and retention rate are assumed to be constant, sales, earnings, assets, dividends and equity will grow at the same rate.

${ }^{10}$ Empirical evidence has not given unequivocal support to the Capital Asset Pricing Model. Jensen (1972) surveyed a host of studies which questioned the underlying assumptions of the model. In addition, the survey also cited numerous econometric problems which characterized the model testing efforts.

${ }^{11}$ Three parameters are required for the estimation of the discount rate: (1) the risk free rate; (2) equity risk premium and (3) a measure of individual firm systematic risk. Diverse values resulting from different historical series, and objective as well as subjective evaluations are available to represent each parameter. The discount rates which result from these different estimates would likewise assume rather diverse values.

${ }_{12}^{12}$ The Value Line Beta became available only from 1973 onwards. Betas from 1970-1972 were based on 1973 to 1975 average values.
} 
Exhibit 2

List of Sample Industries

\begin{tabular}{|c|c|}
\hline SIC & Industries \\
\hline 1600 & Construction-Non-Building \\
\hline 2000 & Food and Kindred Products \\
\hline 2010 & Meat Products \\
\hline 2086 & Bottled-Canned Soft Drink \\
\hline 2200 & Textile Mill \\
\hline 2600 & Paper and Allied Products \\
\hline $2711-31$ & Publishing \\
\hline 2800 & Chemical and Allied Products \\
\hline 2830 & Drugs \\
\hline 2911 & Petrol Refining \\
\hline 3000 & Rubber and Miscellaneous Products \\
\hline 3140 & Footwear (except rubber) \\
\hline 3310 & Blast Furnace and Steel Works \\
\hline 3520 & Farm and Garden Machinery \\
\hline 3531 & Construction Machinery \\
\hline 3540 & Metal Working Machinery \\
\hline 3560 & General Industrial Machinery \\
\hline 3570 & Office Computing and Accounting Machines \\
\hline 3573 & Electronic Computing Equipment \\
\hline 3630 & Household Appliances \\
\hline 3662 & Radio TV Transmitting Equipment \\
\hline 3670,79 & Electronic Components and Accessories \\
\hline 3711 & Motor Vehicles and Car Bodies \\
\hline 3714 & Motor Vehicles Parts and Accessories \\
\hline $3720,21,28$ & Aircraft Parts and Accessories \\
\hline 3841 & Surgical and Medical Equipment \\
\hline 4011 & Railroads \\
\hline 4210 & Trucking \\
\hline 4511 & Air Transportation \\
\hline 4811 & Telephone \\
\hline 4830 & Broadcasting \\
\hline 4911 & Electric Services \\
\hline 5311 & Retail-Department Stores \\
\hline 5411 & Retail-Grocery \\
\hline 5812 & Retail-Eating Places \\
\hline 5912 & Retail-Drug \\
\hline 6025 & National Banks \\
\hline 6120 & Savings and Loans \\
\hline 6312 & Life Insurance \\
\hline 6332 & Property and Casualty Insurance \\
\hline 9997 & Conglomerates \\
\hline
\end{tabular}

bring in a diversity of industry environments, each with sufficient degrees of freedom to support single industry analysis if necessary. The final sample consisted of over 4000 observations pertaining to over 400 companies in 42 industries (Exhibit 2). These included manufacturing, transportation and financial institutions.

Empirical analyses were conducted in three samples: (1) the undifferentiated or mixed value performance sample $(n=4048)$; (2) the value erosion sample where ROE is less than $K_{E}(n=2415)$, and (3) the value creation sample where ROE exceeds $K_{E}$ $(n=1630)$. The subdivision of sample (1) into the value erosion sample (2) and the value creation sample (3) is necessary to accommodate the different directions hypothesized for the growth coefficients in the two latter samples (see Table 1). Due to space limitation, Pearson Correlation coefficients within the three samples will not be printed here but can be obtained from the author upon request. 


\section{Results}

Standardized coefficients pertaining to the regression of market price to book ratio $(M / B)$ in Models $(A),(B),(C)$ in the three samples are listed in Tables $2-4$. In the above tables, equations (1)-(6) represent alternative specifications for Model $(A)$, equations (7)-(12) for Model $(B)$, equations (13)-(16) for Model $(C)$, and equation (17) for Model $(D)$. On the whole, Model $(A)$ had the highest average $R^{2}$ in the mixed value performance and value erosion samples while Model $(B)$ had the highest $R^{2}$ in the value creation sample.

\section{Mixed Value Performance Sample}

In this sample (Table 2), $R^{2}$ for the 16 regressions ranged from 0.93 to 0.141 . The variables which emerged significant at the $5 \%$ level in every equation were Growth in Sales $\left(G_{2}\right)$, Growth in Assets $\left(G_{4}\right)$, Growth in Equity $\left(G_{5}\right)$, and the Market index $(M)$. Return on Equity was significant in eight out of 12 equations, while the ratio Return on Equity to Cost of Equity was significant in three out of four entries. Among these variables, the explanatory factors with the higher standardized Beta coefficients were Asset Growth (0.271 to 0.291), the Market Index (0.193 to 0.211) and Return on Equity (0.034 to 0.209$)$.

Since the hypotheses pertain to the direction of the coefficients, a comparison of the actual versus expected directions is called for. For ROE and ROE $/ K_{E}$, the coefficients were positive as expected. The results also supported the negative coefficients projected for $K_{E}$. Yet these coefficients were not statistically significant. Insignificant and mixed directions characterized the coefficients corresponding to the inverse of the discount factor $\left(1 / K_{E}\right)$.

In this sample, no prior direction was specified for the growth variables. The regressions yielded positive coefficients with respect to growth in earnings per share, asset and equity; and negative coefficients for growth in dividends and sales. Also unspecified, the directions for the market index coefficients were consistently positive in all 16 equations. On the whole, the Pearson correlation matrix indicated no multicollinearity problems except between growth in sales and assets. While their beta coefficients adopted different directions, both variables were positively correlated with the dependent variable and with each other. Asset growth, however, was more highly correlated with the valuation ratio and as the results showed, dominated over sales growth in the regressions.

\section{Value Erosion Sample}

In the value erosion sample (Table 3 ), we find that explanatory power was reduced substantially, with $R^{2}$ ranging from 0.042 to 0.091 . The results, however, were markedly similar with the previous sample. No major changes can be cited in the directions of the coefficients although one variable, growth in sales, had dropped out of the $5 \%$ level of significance. With the addition of equity growth (standardized Beta coefficients ranging from 0.107 to 0.132 ), the variables with the stronger influence were still Asset Growth (0.142 to 0.166$)$, the Market Index (0.101 to 0.116$)$ and Return on Equity ( -0.015 to 0.217$)$.

As expected, primarily positive coefficients were obtained for $\mathrm{ROE}$ and $\mathrm{ROE} / K_{E}$, and negative coefficients for $K_{E}$. The growth variables, however, did not conform to expectations of negative coefficients. Only two growth variables corresponding to dividends and sales were negative; yet these were not statistically significant. On the other hand, the significant growth variables pertaining to assets and equity were positive. Growth in earnings per share was also positive, though not significant. These positive directions were not spurious but were consistent with the positive first order 
TABLE 2

Standardized Regression Coefficients in the Pooled Undifferentiated Sample

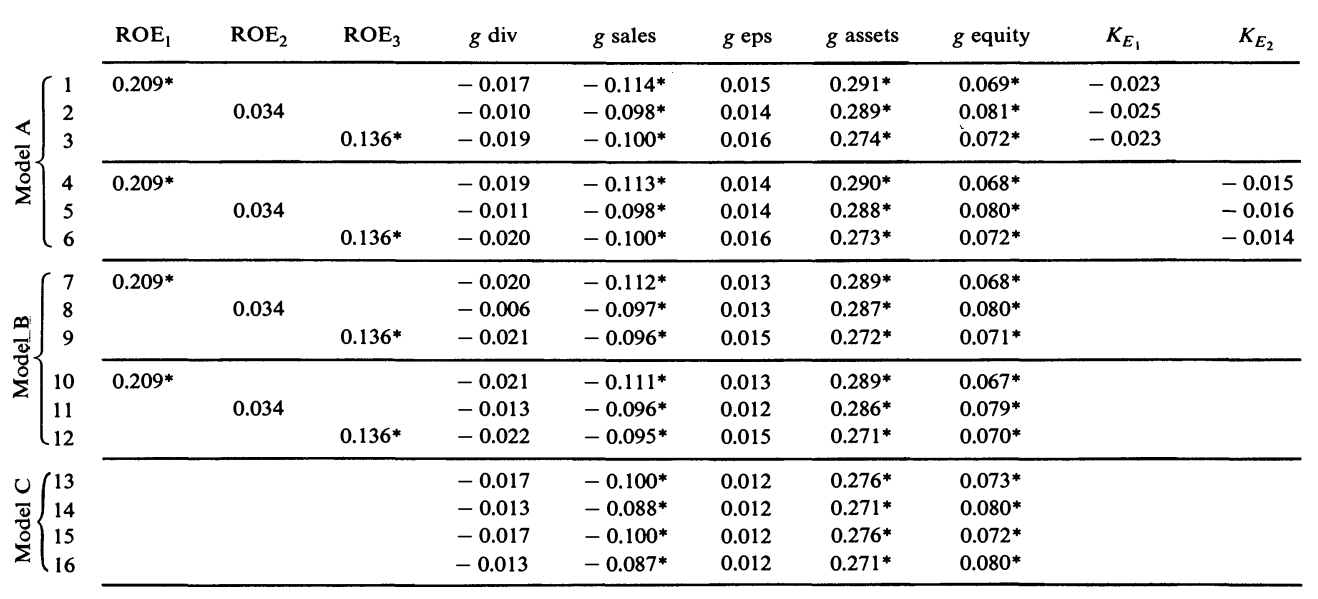

$*=$ significant at $\alpha=5 \%$ level.

correlation between the growth variables and the valuation ratio. A similar pattern of correlations and coefficient directions indicated the same multicollinearity problems between growth in sales and assets. As in the total sample, the current regressions also produced consistently positive and significant coefficients with respect to the market index.

\section{Value Creation Sample}

Regressions within the value creation sample (Table 4) generated slightly more encouraging results. $R^{2}$ increased to a higher range of 0.233 to 0.247 . The variables which emerged as significant also differed somewhat from the outcome of the two previous sets of analyses. These variables included the discount factor $\left(K_{E}\right)$, its inverse $\left(1 / K_{E}\right)$, the market index $(M)$ and growth in dividends, sales and assets. The current emphasis has shifted away from the earlier significant variables, Return on Equity and Growth in equity. The strength of the coefficients likewise increased and the more

TABLE 3

Standardized Regression Coefficients in the Pooled Value Erosion Sample

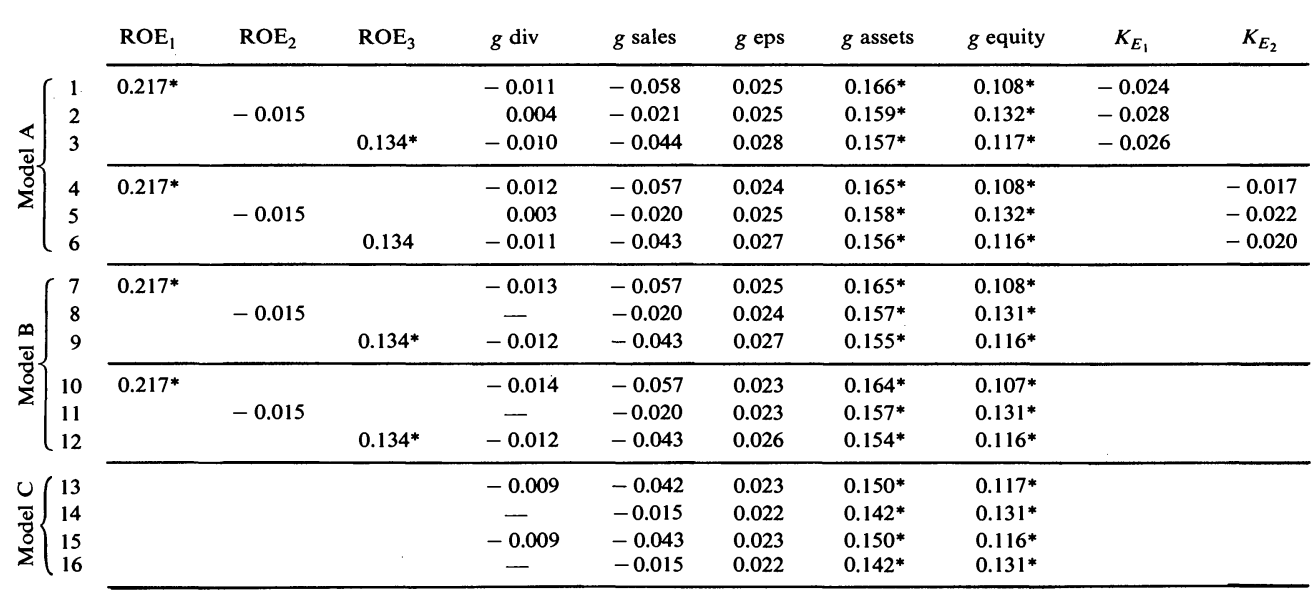

$*$ significant at $\alpha=5 \%$ level 
TABLE 2 (continued)

\begin{tabular}{|c|c|c|c|c|c|c|c|c|}
\hline $1 / K_{E_{1}}$ & $1 / K_{E_{2}}$ & $\mathrm{ROE}_{1} / K_{E_{1}}$ & $\mathrm{ROE}_{2} / K_{E_{1}}$ & $\mathrm{ROE}_{1} / K_{E_{2}}$ & $\mathrm{ROE}_{2} / K_{E_{2}}$ & $M$ & $R^{2}$ & $\begin{array}{c}\text { Degrees of } \\
\text { Freedom }\end{array}$ \\
\hline & & & & & & $0.200^{*}$ & 0.141 & 2960 \\
\hline & & & & & & $0.193^{*}$ & 0.100 & 2960 \\
\hline & & & & & & $0.198^{*}$ & 0.115 & 2960 \\
\hline & & & & & & $0.205^{*}$ & 0.140 & 2960 \\
\hline & & & & & & $0.198^{*}$ & 0.099 & 2960 \\
\hline & & & & & & $0.203^{*}$ & 0.115 & 2960 \\
\hline 0.004 & & & & & & $0.208^{*}$ & 0.140 & 2960 \\
\hline 0.005 & & & & & & $0.201^{*}$ & 0.0985 & 2960 \\
\hline \multirow[t]{8}{*}{0.004} & & & & & & $0.207^{*}$ & 0.115 & 2960 \\
\hline & -0.004 & & & & & $0.211^{*}$ & 0.140 & 2960 \\
\hline & -0.002 & & & & & $0.205^{*}$ & 0.098 & 2960 \\
\hline & -0.004 & & & & & $0.210^{*}$ & 0.115 & 2960 \\
\hline & & $0.150^{*}$ & & & & $0.206^{*}$ & 0.114 & 3059 \\
\hline & & & 0.034 & & & $0.204^{*}$ & 0.093 & 3059 \\
\hline & & & & $0.154^{*}$ & & $0.207^{*}$ & 0.115 & 3059 \\
\hline & & & & & $0.035^{*}$ & $0.204^{*}$ & 0.093 & 3059 \\
\hline
\end{tabular}

prominent variables were the market index $(0.379$ to 0.440$)$, growth in assets $(0.361$ to $0.397)$ and growth in sales $(-0.216$ to -0.196$)$.

In this sample the directions of the results were surprising. The discount rate yielded a set of positive coefficients and the opposite was true for its inverse $\left(1 / K_{E}\right)$. Hence, firms with higher risks would enjoy higher market to book ratios. Yet this result is conceivable within the current sample where firms had more than recovered their cost of capital. Thus it appears that high risk would not penalize firms which were capable of adequately compensating shareholders for their risk assumption. Though positive as expected, the impact of Return on Equity and the ratio of Return on Equity to the Cost of Capital was not as pronounced as the discount factor itself.

The coefficients pertaining to growth also turned out contrary to expectations. Except for the positive and significant asset growth coefficients, all other growth variables assumed negative directions. Of these, growth in dividends and sales were significant. These results also corroborated with the negative Pearson correlations

TABLE 3 (continued)

\begin{tabular}{|c|c|c|c|c|c|c|c|c|}
\hline $1 / K_{E_{1}}$ & $1 / K_{E_{2}}$ & $\mathrm{ROE}_{1} / K_{E_{1}}$ & $\mathrm{ROE}_{2} / K_{E_{1}}$ & $\mathrm{ROE}_{1} / K_{E_{2}}$ & $\mathrm{ROE}_{2} / K_{E_{2}}$ & $M$ & $R^{2}$ & $\begin{array}{c}\text { Degrees of } \\
\text { Freedom }\end{array}$ \\
\hline & & & & & & $0.107^{*}$ & 0.091 & 1698 \\
\hline & & & & & & $0.101^{*}$ & 0.046 & 1698 \\
\hline & & & & & & $0.108^{*}$ & 0.062 & 1698 \\
\hline & & & & & & $0.111^{*}$ & 0.091 & 1698 \\
\hline & & & & & & $0.105^{*}$ & 0.046 & 1698 \\
\hline & & & & & & $0.113^{*}$ & 0.062 & 1698 \\
\hline 0.009 & & & & & & $0.113^{*}$ & 0.091 & 1698 \\
\hline 0.012 & & & & & & $0.106^{*}$ & 0.045 & 1698 \\
\hline \multirow[t]{8}{*}{0.011} & & & & & & $0.114^{*}$ & 0.062 & 1698 \\
\hline & 0.005 & & & & & $0.115^{*}$ & 0.090 & 1698 \\
\hline & 0.009 & & & & & $0.109^{*}$ & 0.045 & 1698 \\
\hline & 0.007 & & & & & $0.116^{*}$ & 0.062 & 1698 \\
\hline & & $0.139^{*}$ & & & & $0.114^{*}$ & 0.061 & 1698 \\
\hline & & & -0.023 & & & $0.111^{*}$ & 0.042 & 1698 \\
\hline & & & & $0.144^{*}$ & & $0.114^{*}$ & 0.062 & 1698 \\
\hline & & & & & -0.022 & $0.111^{*}$ & 0.042 & 1698 \\
\hline
\end{tabular}


TABLE 4

Standardized Regression Coefficients in the Pooled Value Creation Sample

\begin{tabular}{|c|c|c|c|c|c|c|c|c|c|c|}
\hline & & $\mathrm{ROE}_{1}$ & $\mathrm{ROE}_{2}$ & $\mathrm{ROE}_{3}$ & $g$ div & $g$ sales & $g$ eps & $g$ assets & $g$ equity & $K_{E_{1}}$ \\
\hline \multirow{6}{*}{$\begin{array}{l}< \\
\bar{\Phi} \\
\frac{\delta}{\Sigma}\end{array}$} & 1 & 0.036 & & & $-0.058^{*}$ & $-0.209^{*}$ & -0.014 & $0.383^{*}$ & -0.041 & $0.085^{*}$ \\
\hline & 2 & & 0.043 & & $-0.062^{*}$ & $-0.199^{*}$ & -0.016 & $0.367^{*}$ & -0.047 & $0.092^{*}$ \\
\hline & 3 & & & $0.049 *$ & $-0.062^{*}$ & $-0.199^{*}$ & -0.014 & $0.368^{*}$ & -0.045 & $0.090^{*}$ \\
\hline & 4 & 0.033 & & & $-0.059^{*}$ & $-0.208^{*}$ & -0.016 & $0.381^{*}$ & -0.043 & \\
\hline & 5 & & 0.043 & & $-0.063^{*}$ & -0.198 & -0.017 & $0.364^{*}$ & $-0.049^{*}$ & \\
\hline & 6 & & & $0.049 *$ & $-0.063^{*}$ & $-0.199^{*}$ & -0.016 & $0.366^{*}$ & -0.047 & \\
\hline \multirow{6}{*}{$\begin{array}{l}m \\
\bar{d} \\
\frac{m}{\Sigma}\end{array}$} & 7 & 0.031 & & & -0.059 & $-0.206^{*}$ & -0.016 & $0.378^{*}$ & -0.043 & \\
\hline & 8 & & 0.042 & & $-0.063^{*}$ & $-0.196^{*}$ & -0.017 & $0.363^{*}$ & $-0.049^{*}$ & \\
\hline & 9 & & & 0.048 & $-0.063^{*}$ & $-0.196^{*}$ & -0.016 & $0.364^{*}$ & -0.047 & \\
\hline & 10 & 0.028 & & & $-0.059^{*}$ & $-0.205^{*}$ & -0.018 & $0.376^{*}$ & -0.046 & \\
\hline & 11 & & 0.043 & & $-0.063^{*}$ & $-0.196^{*}$ & -0.019 & $0.361^{*}$ & $-0.051^{*}$ & \\
\hline & 12 & & & 0.048 & $-0.063^{*}$ & $-0.196^{*}$ & -0.017 & $0.362^{*}$ & $-0.049^{*}$ & \\
\hline \multirow{4}{*}{$\begin{array}{l}u \\
\frac{\tilde{d}}{\delta} \\
\Sigma\end{array}$} & $(13$ & & & & -0.046 & $-0.216^{*}$ & -0.011 & $0.397^{*}$ & -0.034 & \\
\hline & 14 & & & & $-0.049^{*}$ & $-0.205^{*}$ & -0.015 & $0.379^{*}$ & -0.041 & \\
\hline & 15 & & & & -0.046 & $-0.216^{*}$ & -0.011 & $0.396^{*}$ & -0.035 & \\
\hline & 16 & & & & -0.049 & $-0.206^{*}$ & -0.015 & $0.380^{*}$ & -0.041 & \\
\hline
\end{tabular}

$*$ significant at the $\alpha=5 \%$ level.

between the dependent variable and three of the four negative growth variables (dividends, earnings per share, and equity). The negative coefficient pertaining to the sales growth variable was, again, a spurious outcome of its correlation with asset growth and the subsequent multicollinearity problem. Unchanged from the two earlier samples, the market index was positive and significant in all 16 equations.

In the regressions conducted above, pooling across diverse industries introduced a high degree of heterogeneity which would be partially responsible for the low $R^{2}$ thus far observed. To enhance homogeneity, the analysis was repeated within ten samples of single industries with the highest number of observations. These included rubber and allied products $(N=120)$, national banks $(n=130)$, conglomerates $(n=190)$, drugs $(n=150)$, chemicals and allied products $(n=140)$, construction in the nonbuilding sector $(n=130)$, petroleum refining $(n=140)$, blast furnace and steel products $(n=130)$, paper and allied products $(n=130)$ and air transportation $(n=130)$. Instead of four models and 16 equations, only equation (1) which consistently demonstrated high explanatory power was carried forward into the single industry analyses. Within each industry, regressions were again conducted three times in (1) the undifferentiated or mixed value performance sample, (2) the value erosion sample, and (3) the value creation sample. Standardized beta coefficients are reported in Tables $5-7$.

\section{Single Industries: Mixed Value Performance Samples}

In these samples, $R^{2}$ increased substantially to a range of 0.255 to 0.728 (Table 5). In nine out of ten industries (with the exception of the steel industry), Return on Equity and the Market Index were positive and significant. However, our ability to generalize across industries stops here. In some industries (rubber products, banks, construction, petrol refining, paper products), risk was positively associated with the valuation ratio; yet in others, this relationship was negative (conglomerates, drugs, chemical products, steel and air transportation). Perhaps in the first group of industries, perceived risk was significantly below the unacceptable level, and thus willingness to assume greater risk would enlarge the opportunity set, thus enhancing rather than threatening the attractiveness of the industries. The relationship between each of the five growth variables to the valuation ratio varied greatly across the ten industries and did not yield a standard pattern of growth realtionships. 
TABLE 4 (continued)

\begin{tabular}{|c|c|c|c|c|c|c|c|c|c|}
\hline$K_{E_{2}}$ & $1 / K_{E_{1}}$ & $1 / K_{E_{2}}$ & $\mathrm{ROE}_{1} / K_{E_{1}}$ & $\mathrm{ROE}_{2} / K_{E_{1}}$ & $\mathrm{ROE}_{1} / K_{E_{2}}$ & $\mathrm{ROE}_{2} / K_{E_{2}}$ & $M$ & $R^{2}$ & $\begin{array}{c}\text { Degrees of } \\
\text { Freedom }\end{array}$ \\
\hline & & & & & & & $0.420^{*}$ & 0.239 & 1252 \\
\hline & & & & & & & $0.420^{*}$ & 0.239 & 1252 \\
\hline & & & & & & & $0.421^{*}$ & 0.239 & 1252 \\
\hline $0.098^{*}$ & & & & & & & $0.418^{*}$ & 0.241 & 1252 \\
\hline $0.104^{*}$ & & & & & & & $0.419^{*}$ & 0.241 & 1252 \\
\hline \multirow[t]{11}{*}{$0.102^{*}$} & & & & & & & $0.419^{*}$ & 0.242 & 1252 \\
\hline & $-0.118^{*}$ & & & & & & $0.439^{*}$ & 0.243 & 1252 \\
\hline & $-0.124^{*}$ & & & & & & $0.440^{*}$ & 0.243 & 1252 \\
\hline & $-0.122^{*}$ & & & & & & $0.440^{*}$ & 0.244 & 1252 \\
\hline & & $-0.128^{*}$ & & & & & $0.433^{*}$ & 0.245 & 1252 \\
\hline & & $-0.133^{*}$ & & & & & $0.434^{*}$ & 0.246 & 1252 \\
\hline & & $-0.132^{*}$ & & & & & $0.434^{*}$ & 0.247 & 1252 \\
\hline & & & $0.050^{*}$ & & & & $0.381^{*}$ & 0.234 & 1278 \\
\hline & & & & -0.043 & & & $0.379 *$ & 0.233 & 1278 \\
\hline & & & & & 0.047 & & $0.381^{*}$ & 0.234 & 1278 \\
\hline & & & & & & 0.041 & $0.379^{*}$ & 0.233 & 1278 \\
\hline
\end{tabular}

In total, the positive direction hypothesized for Return on Equity was supported in nine out of ten industries, and the negative direction for the discount rate was supported in only five of the ten industries.

\section{Single Industries: Value Erosion Samples}

$R^{2}$ in the value erosion samples were quite high and ranged from 0.168 to as high as 0.915 for the steel industry (Table 6). However results for this industry which yielded a significant and negative Return on Equity coefficient was counterintuitive. Further interpretation would require a more in-depth historical examination of the individual steel companies. These coefficients presumably reflected the more uncertain investor perceptions of the troubled producers within a highly turbulent industry environment.

In this set of regressions, Return on Equity and the Market index were still the

TABLE 5

Standardized Beta Coefficients in Ten Selected Industries: Undifferentiated Samples

\begin{tabular}{|c|c|c|c|c|c|c|c|c|c|c|}
\hline & 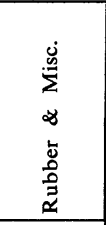 & 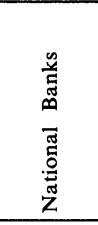 & 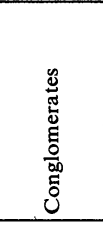 & $\begin{array}{l}n \\
\text { 品 } \\
\text { 吉 } \\
\end{array}$ & 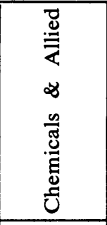 & 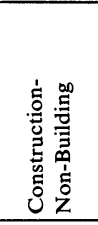 & 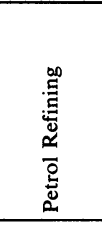 & 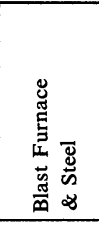 & 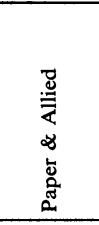 & 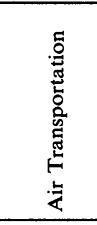 \\
\hline ROE & $0.180^{*}$ & $0.565^{*}$ & $0.309^{*}$ & $0.621^{*}$ & $0.415^{*}$ & $0.417^{*}$ & $0.348^{*}$ & $-0.788^{*}$ & $0.786^{*}$ & $0.279 *$ \\
\hline$K_{E}$ & $0.208^{*}$ & 0.032 & $-0.320^{*}$ & $-0.174^{*}$ & -0.075 & 0.176 & 0.080 & -0.019 & 0.074 & -0.081 \\
\hline$g_{\text {div }}$ & 0.040 & -0.204 & -0.101 & 0.100 & -0.011 & - & -0.143 & 0.041 & 0.089 & 0.136 \\
\hline$g_{\text {sales }}$ & -0.101 & 0.046 & 0.157 & $0.389^{*}$ & $0.316^{*}$ & 0.094 & -0.171 & -0.115 & - & 0.148 \\
\hline$g_{\text {eps }}$ & 0.078 & $-0.245^{*}$ & -0.092 & $-0.221^{*}$ & -0.180 & -0.088 & -0.039 & -0.131 & $-0.224^{*}$ & -0.034 \\
\hline$g_{\text {assets }}$ & $0.746^{*}$ & 0.104 & -0.068 & -0.196 & 0.131 & 0.048 & $0.269^{*}$ & $0.226^{*}$ & $0.241^{*}$ & 0.047 \\
\hline$g_{\text {equity }}$ & 0.021 & 0.142 & -0.078 & -0.038 & -0.014 & 0.012 & $-0.249^{*}$ & 0.084 & -0.138 & - \\
\hline$M$ & $0.325^{*}$ & $0.662^{*}$ & $0.274^{*}$ & $0.455^{*}$ & $0.690^{*}$ & $0.390^{*}$ & $0.434^{*}$ & -0.025 & $0.588^{*}$ & 0.730 \\
\hline$R^{2}$ & 0.671 & 0.671 & 0.327 & 0.728 & 0.539 & 0.255 & 0.329 & 0.701 & 0.431 & 0.533 \\
\hline$D F$ & 106 & 99 & 180 & 138 & 131 & 115 & 130 & 118 & 119 & 122 \\
\hline
\end{tabular}

* = significant at the $\alpha=5 \%$ level 
TABLE 6

Standardized Beta Coefficients in Ten Selected Industries: Value Erosion Samples

\begin{tabular}{|c|c|c|c|c|c|c|c|c|c|c|}
\hline & 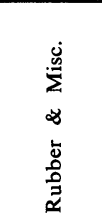 & 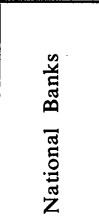 & 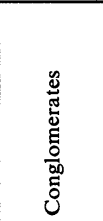 & $\stackrel{\infty}{\vec{b}}$ & 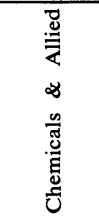 & 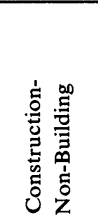 & 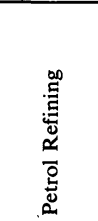 & 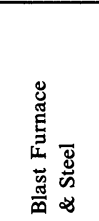 & 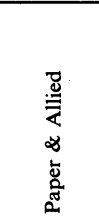 & 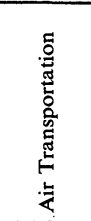 \\
\hline ROE & $0.285^{*}$ & $0.620^{*}$ & 0.141 & -0.078 & 0.049 & 0.217 & 0.193 & $-0.903^{*}$ & $0.566^{*}$ & $0.245^{*}$ \\
\hline$K_{E}$ & $0.301^{*}$ & 0.048 & -0.162 & -0.425 & -0.302 & 0.161 & $-0.254^{*}$ & -0.205 & 0.180 & -0.040 \\
\hline$g_{\text {div }}$ & $0.230^{*}$ & 0.087 & -0.064 & 0.050 & - & -0.073 & $-0.153^{*}$ & $0.096^{*}$ & -0.058 & $0.192^{*}$ \\
\hline$g_{\text {sales }}$ & $-0.385^{*}$ & - & 0.250 & $-0.371^{*}$ & 0.216 & -0.094 & -0.340 & $-0.118^{*}$ & $0.386^{*}$ & 0.106 \\
\hline$g_{\text {eps }}$ & 0.095 & $-0.267^{*}$ & -0.163 & 0.137 & 0.080 & - & $0.266^{*}$ & -0.059 & -0.268 & -0.082 \\
\hline$g_{\text {assets }}$ & $0.515^{*}$ & -0.135 & -0.151 & 0.249 & $0.402^{*}$ & 0.186 & $0.456^{*}$ & $0.164^{*}$ & -0.219 & 0.114 \\
\hline$g_{\text {equity }}$ & -0.156 & -0.133 & -0.020 & -0.094 & 0.055 & 0.089 & $-0.381^{*}$ & 0.014 & $-0.334^{*}$ & -0.054 \\
\hline$M$ & $0.606^{*}$ & $0.762^{*}$ & $0.359^{*}$ & 0.288 & $0.544^{*}$ & $0.379^{*}$ & 0.290 & -0.091 & $0.676^{*}$ & $0.772^{*}$ \\
\hline$R^{2}$ & 0.607 & 0.803 & 0.238 & 0.543 & 0.458 & 0.168 & 0.417 & 0.915 & 0.410 & 0.528 \\
\hline$D F$ & 79 & 47 & 117 & 11 & 77 & 69 & 64 & 81 & 73 & 99 \\
\hline
\end{tabular}

* = significant at the $\alpha=5 \%$ level

important explanatory factors though they were not as consistently dominant as in the undifferentiated samples. Hypothesized directions were obtained in eight industries for Return on Equity (+), and in six industries for the cost of equity (-). Of the 47 coefficients possible for the growth variables, only 24 were negative as projected. Directions for the various growth variables did not form a common pattern across industries. Presumably, each pattern would vary with the growth opportunities, competitive dynamics and structure within the individual industry. All industries, except for the steel producers, yielded positive coefficients with respect to the Market index.

TABLE 7

Standardized Beta Coefficients in Ten Selected Industries: Value Creation Samples

\begin{tabular}{|c|c|c|c|c|c|c|c|c|c|c|}
\hline & 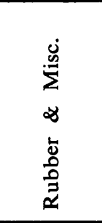 & 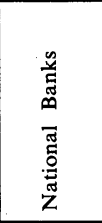 & 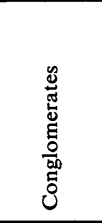 & 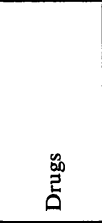 & 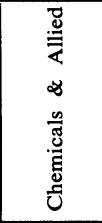 & 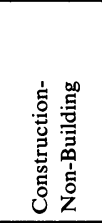 & 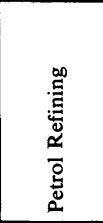 & 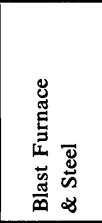 & 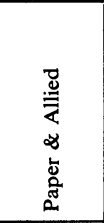 & 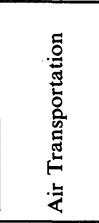 \\
\hline ROE & $0.479^{*}$ & $0.577^{*}$ & 0.100 & $-0.613^{*}$ & $0.638^{*}$ & - & $0.395 *$ & $0.576^{*}$ & $0.529^{*}$ & -0.194 \\
\hline$K_{E}$ & -0.055 & 0.301 & $-0.264^{*}$ & $-0.237^{*}$ & -0.120 & 0.351 & 0.229 & 0.271 & -0.116 & -0.120 \\
\hline$g_{\text {div }}$ & -0.022 & -0.151 & - & 0.123 & 0.052 & -0.054 & -0.064 & - & 0.288 & -0.088 \\
\hline$g_{\text {sales }}$ & -0.391 & 0.144 & $-0.286^{*}$ & 0.188 & 0.229 & 0.315 & 0.027 & -0.067 & - & $0.767^{*}$ \\
\hline$g_{\text {eps }}$ & 0.204 & $-0.522^{*}$ & 0.051 & $-0.118^{*}$ & $-0.383^{*}$ & 0.034 & -0.271 & -0.123 & -0.147 & 0.050 \\
\hline$g_{\text {assets }}$ & $0.971^{*}$ & 0.208 & $0.316^{*}$ & -0.033 & -0.097 & -0.148 & 0.054 & $0.643^{*}$ & $0.362^{*}$ & $-0.792^{*}$ \\
\hline$g_{\text {equity }}$ & 0.045 & 0.207 & -0.176 & -0.121 & -0.098 & -0.167 & $-0.164^{*}$ & $-0.311^{*}$ & -0.172 & 0.085 \\
\hline$M$ & 0.225 & $0.932 *$ & 0.515 & $0.471^{*}$ & 0.860 & $0.522^{*}$ & $0.473^{*}$ & $0.442^{*}$ & $0.657^{*}$ & $0.779 *$ \\
\hline$R^{2}$ & 0.823 & 0.620 & 0.477 & 0.774 & 0.775 & 0.227 & 0.372 & 0.675 & 0.607 & 0.789 \\
\hline$D F$ & 18 & 44 & 55 & 118 & 46 & 37 & 56 & 29 & 37 & 13 \\
\hline
\end{tabular}

* = significant at the $\alpha=5 \%$ level 
TABLE 8

Unstandardized Beta Coefficients: Regressions of Actual Market Valuation Ratios on Predicted Valuation Ratios Based on the Constant Growth Model

\begin{tabular}{|c|c|c|c|c|c|c|c|c|c|c|c|c|}
\hline & & $\begin{array}{l}\frac{\pi}{8} \\
8 \\
\end{array}$ & 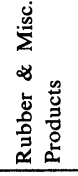 & 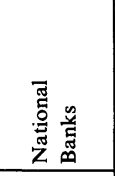 & 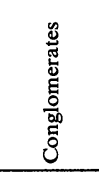 & $\begin{array}{l}\text { कू. } \\
\text { 点 } \\
\end{array}$ & 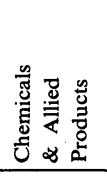 & 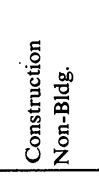 & 홀 & 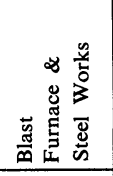 & 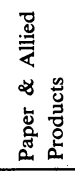 & 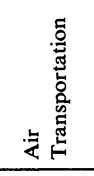 \\
\hline \multirow{2}{*}{ Undifferentiated } & $\hat{v} / B$ & 0.0120 & 0.0494 & 0.0041 & 0.0042 & 0.0266 & 0.0355 & 0.0023 & 0.0340 & $-0.0487^{*}$ & 0.0178 & 0.0117 \\
\hline & $R^{2}$ & 0.0027 & 0.0199 & 0.0015 & 0.0007 & 0.0129 & 0.0074 & 0.0018 & 0.0033 & 0.2032 & 0.0091 & 0.0028 \\
\hline \multirow{2}{*}{ Value Erosion } & $\hat{v} / B$ & 0.0088 & 0.0196 & $0.5635^{*}$ & -0.0033 & - & 0.0061 & 0.0435 & - & $-0.0603^{*}$ & 0.0515 & 0.0080 \\
\hline & $R^{2}$ & 0.0019 & 0.0268 & 0.1464 & 0.0011 & - & 0.0007 & 0.0062 & - & 0.3429 & 0.0240 & 0.0018 \\
\hline \multirow{2}{*}{ Value Creation } & $\hat{v} / B$ & 0.0106 & 1.7573 & -0.0060 & 0.1167 & 0.0250 & -0131 & -0.0014 & 0.0087 & 0.0267 & 0.0046 & -0.4058 \\
\hline & $R^{2}$ & 0.0014 & 0.1280 & 0.0058 & 0.0121 & 0.0132 & 0.0002 & 0.0014 & 0.0003 & 0.0446 & 0.0009 & 0.0387 \\
\hline
\end{tabular}

* = significant at the $\alpha=5 \%$ level

\section{Single Industries: Value Creation Samples}

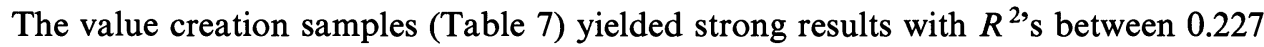
and 0.823 . In this set of regressions the Market index and Return on Equity regained their positive and significant impact. Support for the hypotheses, nevertheless, did not strengthen. Return on Equity was generally positive (in eight out of nine equations) while the cost of equity assumed negative coefficients in only six cases. The growth coefficients were no more likely to be positive in these samples than they were negative in the value erosion samples. Considering all equations, only 25 of the 47 growth efficients were positive. Among these, growth in sales and assets tended more of ten to have a positive impact on the valuation ratio.

\section{The Constant Growth Model}

Finally, the Constant Growth Model was empirically evaluated in the form represented by Model $(D)$. Regressions were performed in the pooled sample and also within each of the ten selected industries. For these analyses, the mixed value performance sample was likewise divided into the value erosion and creation samples. Since only one independent variable was considered in the regressions, there was no need for variable standardization. The unstandardized Beta Coefficients are reported in Table 8.

The regressions generated extremely weak results. Only three of 31 unstandardized coefficients emerged significant at the 5\% level. Values of the coefficients were substantially short of the unity level as specified in hypothesis $\mathrm{V}$. The average value of all 31 Beta coefficients was 0.0745 . Predictably, given the above outcomes, the percentage of explained variance would also be minimal. The average $R^{2}$ was 0.0343 . These results did not improve with increased homogeneity within the individual industry subgroups, the value erosion samples and the value creation samples.

\section{Discussion and Conclusion}

$R$-Squares in the pooled, highly heterogeneous samples were very low. Among the three samples, the value creation sample yielded stronger results than the mixed value performance and value erosion samples. The latter likely reflected the more turbulent conditions and uncertain investor evaluations of businesses which were unable to satisfy stockholders' required return.

In the above pooled samples, support for hypothesis I was strong. The Return on Equity coefficients were almost always positive as specified. Results pertaining to the cost of equity were also consistent with hypothesis II except in the value creation 
samples. Indeed, for these businesses which exceeded their shareholders' required return for risk assumption, higher risks only led to higher valuation ratios. The results did not provide clear support for the growth variables. They were no more likely to be positive in the value creation samples (hypothesis III) than they were negative in the value erosion samples (hypothesis IV).

As we move into the industry subsamples, percentages of explained variance increased substantially and yielded $R^{2}$,s as high as 0.90 . This higher explanatory power was primarily attributable to the market index and the firm's return on equity. The role of the other independent variables was not dominant. Support for the hypothesized directions pertaining to the discount rate and the growth variables did not increase in strength or clarity. No common patterns appear to characterize the regression results across industries.

Finally, the fit of the constant growth model was poor and the wide disparity between the observed market valuation ratio and the model estimates was clearly indicated by the results. This last set of results failed to support the constant growth model as specified in hypothesis $\mathrm{V}$.

Overall, the findings were not encouraging. $R$-squares in the pooled samples were poor. Though explanatory power improved with increased homogeneity in the single industry samples, consistent and strong support for the hypotheses failed to emerge. Rather than dismissing these results, the implications of weak statistical significance should be carefully noted.

The value-based models discussed herein are frequently presented as deterministic predictors of firm value. As such, expectations can be placed on signs of regression coefficients going in the specified directions, strong coefficients and high percentages of explained variance. In this study, when all of the above is absent, what then can we conclude about the models?

One, the Constant Growth Model and to some extent the Two-Stage Model are based on equilibrium assumptions of long-term constant behavior. The single rates of profitability, rate and growth subsumed in these models provide perhaps an overly simplistic view relative to the complex firm reality perceived and evaluated by shareholders. To the extent that such estimates depict only a fraction of the firm's entire life cycle, their explanatory power of firm value will be partial and likewise limited.

One may, of course, choose to view such equilibrium rates as the average behavior of the firm. Yet such averages do not account for the timing of cash flows and different levels of risk which accompany a firm into the different stages of growth, maturity, potential decline and regeneration.

The estimation of long-term equilibrium rates based solely on the historical experience of the firm constitutes the second problem. The reliance on historical data is necessary because reliable forecasts of future equilibrium behavior are not available. This, however, should not be viewed merely as a research obstacle since industry users are similarly constrained by the forecasting problem. In light of the poor fit of the models in this study, unless forecasted values significantly depart from such historical data, model performance would not be much improved. Admittedly, current conditions may be rather poor indicators of future equilibrium. Nevertheless, without embarking on a largely hypothetical exercise, there is sometimes little evidence which permits managers to specify or justify any other scenarios, including those which will contribute to the fit of the models.

Both of these problems contribute to the more fundamental concern that empirical validity of value-based planning models as predictors of firm value still has not been demonstrated. On what basis should we encourage the further application of such models when their empirical success has not yet been established? One can argue that 
such models are premised on sound theoretical foundations and hence its strong following and intuitive appeal can be justified. We must note from the earlier discussion, however, that the contributions of these models are not their theoretical insights. These, after all, are not unfamiliar to any student of Finance and Strategic Management. Their distinctive value-added was the mathematical bridge which enables managers to quantify the value impact of strategic decisions. On this selling point of quantitative exactitude, the performance of the models remains a promise, not a reality.

Perhaps a more constructive approach is to view these models as embryonic developments before solutions accommodating more complex reality can be found. In the same view, results from these models should be judiciously treated as "rough cuts" with the understanding that attendant assumptions are quite unrealistic.

While acceptable under practical circumstances, this attitude must simultaneously foster genuine attempts at model testing and evaluation. Efforts should be made to address second-generation questions pertaining to the level of confidence to be placed on such "rough" estimates, how users can accommodate the limitations of the model, model improvements to provide for a more acceptable representation of the firm and yield better predictors of firm value.

Overall, support for the value-based models in this study is rather weak. The poor statistical results present a strong argument for the need to empirically test the models and rigorously assess their validity. While the underlying theory is sound and the resulting decision process will reflect more conscious attempts at value management, these value-based techniques cannot quite be viewed as quantitative models.

The intent of this study is not to discredit work so far accomplished nor to discourage attention to the strategic valuation challenge. The need for more explicit management of shareholder value will become more, not less, pronounced as environmental pressures prevail. More users will be drawn to such value-based heuristics. Hence, to foresake pursuit in face of current model limitations would be an uncreative response to a serious problem.

The purpose of this paper then is to urge users and proponents to candidly evaluate these models, enabling limitations to be identified, addressed and removed. Without such empirical examination, growth in the strategic management of firm value will likely be stifled by simplistic formulations, misguiding decision heuristics and eventual loss of user confidence.

\section{References}

Archer, Stephen H. And Charles A. D'Ambrosio, Business Finance: Theory and Management, Second Ed., Macmillan, New York, 1972.

Baumol, William T., "Business Behavior," Values and Growth, Harcourt, Brace and World, New York, 1967.

"Beatrice Foods: Adding Tropicana for Broader Nationwide Network," Business Week, (May 15, 1978), 114-6.

"Beatrice Foods Savors a Zestier Cupboard," Business Week, (December 1, 1973), 89-90.

"Beatrice the Acquisitive," Fortune, (June 15, 1975), 252.

Burgman, Roland J., “A Strategic Explanation of Corporate Acquisition Success," (unpublished dissertation), Purdue Úniversity, May 1982.

Cobb, Thomas Walker, JR., "Utilization of Capital Asset Pricing Models in Strategic Planning," (unpublished thesis), Massachusetts Institute of Technology, June 1981.

Cootner, Paul H. (ED.), The Random Character of Stock Market Prices, MIT Press, Cambridge, Mass., 1964.

Copeland, Thomas E. And T. Fred Weston, Financial Theory and Corporate Policy, Addison-Wesley, Philippines, 1979, 334-336.

"Deere: A Countercyclical Expansion to Grab Market Share," Business Week, (November 19, 1979), 79-80.

FAmA, Eugene F., "The Behavior of Stock Prices," J. Business, (January 1965), 34-105.

Francis, Jack C. And Stephen H. Archer, Portofolio Analysis, Prentice-Hall, Englewood Cliffs, N.J., 1971. 
Fruhan, William E., JR., Financial Strategy: Studies in the Creation, Transfer and Destruction of Shareholder Value, Richard D. Irwin, Homewood, Ill., 1979.

Ibbotson, Roger G. AND Rex A. Sinquefield, Stocks, Bonds, Bills and Inflation Historical Returns (1926-1978), Financial Analysts Research Foundation, 1979.

Jensen, Michael C., "Capital Markets: Theory and Evidence," Bell J. Econom. Management Sci., (Autumn 1972), 357-398.

Marakon Associates, The Role of Finance in Strategic Planning, Business Week Conference, 1980.

McCarthy G. D. AND R. E. Healy, Valuing a Company: Practices and Procedures, Ronald Press, New York, 1971.

Moody's Industrial Manual, 1981.

Moody's OTC Industrial Manual, 1981.

“Oh Where, Oh Where-Has My Little Dog Gone? Or My Cash Cow? Or My Star?, " Fortune, (November 2, 1981), 148-154.

RapPaport, Alfred, "Selecting Strategies That Create Shareholder Value," Harvard Business Rev., (MayJune 1981), 139-149.

Salter, Malcom S. and Wolfe A. Weinhold, Diversification Through Acquisition, Free Press, New York, 1979.

Sharpe, William F., Portfolio Theory and Capital Markets, McGraw-Hill, New York, 1970.

Standard and Poor's Statistical Service, New York, 1978-1981.

Strategy and the Shareholder Value: The Value Curve, Strategic Planning Associates, Inc., Washington, D.C., 1981.

Value Line Investment Survey, Arnold and Bernhard, New York, 1982, 333-893.

"Victoria Station Eyes End to Financial Woes," Nation's Restaurant News, (November, 23, 1981), 54.

"Victoria Station Uncorks New Wine Program," Restaurant Business, (December 1981), 80, 82-3.

Woo, Carolyn Y., "A Comparison of Value Creators Against Value Destroyers Along Industry Factors and Value Creation Determinants," Working Paper, Purdue University, January 1983. 